\title{
ВРЕМЯ КАК ОБЪЕКТ ИССЛЕДОВАНИЯ В ЭКОНОМИЧЕСКОЙ НАУКЕ И МЕНЕДЖМЕНТЕ: ОБЗОР СОВРЕМЕННЫХ ТРУДОВ
}

\author{
(c) 2019 Желаева Светлана Эдуардовна \\ доктор экономических наук, доцент, \\ заведующий кафедрой «Менеджмент, маркетинг и коммерция» \\ Восточно-Сибирский государственный университет технологий и управления, Россия, Улан-Удэ \\ E-mail: zhelay@yandex.ru
}

(c) 2019 Жамбалов Жаргал Чингисович

аспирант кафедры «Менеджмент, маркетинг и коммерция»

Восточно-Сибирский государственный университет технологий и управления, Россия, Улан-Удэ

E-mail: zhambalov1995@mail.ru

\section{(c) 2019 Гармаева Эльвира Цыреновна}

кандидат экономических наук, доцент кафедры «Менеджмент, маркетинг и коммерция» Восточно-Сибирский государственный университет технологий и управления, Россия, Улан-Удэ

E-mail: garmaeva.elvira@mail.ru

В статье предпринята попытка провести краткий обзор современных научных работ, посвященных изучению времени в качестве объекта исследования в экономической теории и менеджменте. Исходя из современных взглядов на время сделан вывод о необходимости изучения процессов управления на основе нелинейности времени.

Ключевые слова: время, экономическая теория, менеджмент, тайм-менеджент, нелинейность времени.

Время является объектом исследования многих наук, каждая из которых находит свой предмет изучения времени, исходя из собственной внутренней необходимости, обусловленной стремлением к объективному отражению происходящих явлений и процессов [5]. Это, прежде всего, философия и естествознание. При этом очевиден тот факт, что тема времени касается всех аспектов человеческой жизни: мыслительной, творческой, трудовой, потребительской и др. и должна быть изучена в соответствующих областях научного знания (психология, управление, включая менеджмент и маркетинг). Однако на современном этапе развития экономической науки и менеджмента проблема времени и его влияния на все экономические процессы и процессы управления является малоизученной. Кроме того, преобладает традиционное линейное восприятие времени в качестве, во-первых, шкалы измерения длительности процессов; во-вторых, ограниченного ресурса, требующего рационального использования; в третьих, лимитирующего фактора использования других экономических ресурсов.

Среди трудов отечественных авторов, посвя- щенных изучению времени в экономической науке, можно выделить лишь крайне ограниченный круг.

В монографии В.А. Чемыхина «Время и экономика: Очерки политической экономии времени в концепции К. Маркса» [14] проведен глубокий анализ категории общественного времени и действия закона экономии времени К. Маркса в условиях постиндустриального общества. Теория переключающегося режима воспроизводства основного капитала, разработанная академиком В.И. Маевским, позволяет рассматривать экономическое время К. Маркса, лежащего в основе стоимости, в качестве управляющего фактора, воздействующего на ценностные показатели экономической системы [10]. В рамках теории режима переключающегося воспроизводства В.И. Маевский и С.Ю. Малков рассматривают время как естественный механизм, обеспечивающий круговую и линейную формы движения товарных потоков в открыто-замкнутой системе экономики [11]. На основе методологических принципов теории общего рыночного равновесия Л. Вальраса Е.В. Балацкий рассматривает свободное время в качестве фактора рыночно- 
го равновесия [3]. Работы Е.Л. Толокиной [14] и В.В. Деминой [5] посвящены изучению рабочего времени как основы закона стоимости, а также свободного времени - как цели общественного производства. А.Д. Леванов акцентирует внимание на времени как факторе макроэкономических процессов и рассматривает ценностные аспекты времени в микроэкономике [10]. Желаева С.Э., применив принципы методологического плюрализма и основанной на нем концепции множественности времен, рассматривает время как объект исследования процессов самоорганизации экономических систем. Такой подход расширяет традиционные рамки исследований времени, позволяя рассматривать любой процесс с точки зрения временной онтологии, погруженный в любую среду: товарно-продуктовую, поведенческую, институциональную [6].

К сожалению, количество трудов, посвященных исследованию времени в качестве базового понятия, определяющего все процессы управления, можно свести к единственному. Крючков В.Н. рассматривает различные аспекты временного подхода в менеджменте с точки зрения гипотезы о нелинейности времени и необходимости пересмотра методов долгосрочного и стратегического управления с учетом разных свойств и размерности времени [9].

Причина сложившейся в современной экономике и управлении ситуации ограниченного количества научных трудов, рассматривающих время в качестве непосредственного объекта исследования, на наш взгляд, кроется в том, что представления о времени в экономической теории и менеджменте формировались под влиянием общенаучных концепций в философии и точных науках. Среди общенаучных подходов к пониманию категории времени - объективистского и субъективистского, в точных науках, в частности, физике, возобладал первый подход, где время представляет собой независимую от человеческого сознания форму существования материи. Субъективистское время как результат чувственного восприятия и следствие человеческой психологии было отвергнуто.

Признание объективистской концепции привело к однобокому представлению времени в качестве однородной абсолютной длительности, выраженной в качестве внешней шкалы измерений, физической величины. Исследование динамики развития экономических систем было сведено к моделированию в краткосрочном и долгосрочном периодах, к формированию условий межвременного равновесия, используемых в рамках неоклассического синтеза, в частности, в моделях DSGE (динамических стохастических моделях общего равновесия) и т.д.

Как отмечает Желаева С.Э.: «Большинство теорий экономической науки: классическая (за исключением марксистской), неоклассическая, кейнсианская и неоклассический синтез, учитывают лишь астрономическую форму экономического времени в методологии экономического анализа, используя его как инструмент описания, а не в качестве непосредственного объекта исследования. Такой дескриптивный подход ко времени выражается в возможности наложения на любой экономический процесс временной оси календарного времени и описания длительности, а также последовательности экономических изменений, что существенно упрощает реалии экономического движения и позволяет использовать абстрактные и формализованные модели. Однако данный подход является однобоким, поскольку при множестве разнонаправленных асинхронных процессов, присущих экономике, простое описание временных интервалов и линейных причинно-следственных связей становится недостаточным» [6].

Таким образом, развитие научных подходов к изучению времени в философии и естествознании традиционно задавало направление развития методологии экономической науки, а вслед за ней и методологии менеджмента.

Получивший широкое распространение в 60-70-е годы XX века в качестве отдельной дисциплины в области теоретического и практического управления тайм-менеджмент представляет собой совокупность принципов, методов и технологий эффективной организации и использования времени. Причиной возникновения идей современного тайм-менеджмента можно считать так называемую промышленную революцию. Переход производства от мануфактурного к фабричному с конца XVIII начало XIX веков потребовал новые методы организации работы в условиях массового производства, технического усовершенствования средств производства и накопления капитала.

В этот период взгляды на управление времени формировались под воздействием классического направления экономической теории, представители которой в качестве предмета изучения рассматривали сферу материального 
производства. Материалистическая обусловленность деятельности людей и общества приводит к осознанию действия закона экономии рабочего времени, позволяющего сократить издержки производства и добиться роста производительности труда. Как отмечает К. Маркс: «экономия времени, равно как и планомерное распределение рабочего времени по различным отраслям производства, остается первым экономическим законом на основе коллективного производства. Это становится законом даже в гораздо более высокой степени... чем меньше времени требуется обществу на производство пшеницы, скота и т.д., тем больше времени оно выигрывает для другого производства, материального или духовного. Как для отдельного индивида, так и для общества всесторонность его развития, его потребления и его деятельности зависит от сбережения времени. Всякая экономия, в конечном счете, сводится к экономии времени» [13].

Продиктованные объективной необходимостью принципы экономии времени нашли свое отражение в методах управления производством, в частности, управления временем. Так, Ф.У. Тейлор (1856-1915), являясь основоположником научного управления производством, разработал принципы и методы управления производительностью труда и управления временем, основанные на функциональном администрировании, операционном анализе трудовых операций, календарном планировании, составлении рабочих графиков, фиксации и ведении хронометража деятельности рабочих, установлении нормативов труда и материальной стимуляции за их перевыполнение, качественной подготовки персонала, установлении дисциплины и доброжелательных отношений между предпринимателем и рабочим. Таким образом, разработанные Тейлором методы организации труда и управления производственными процессами во времени были направлены преимущественно на детальное изучение отдельных действий с целью повышения производительности и интенсивности труда каждого работника и оборудования.

Существенный вклад в развитие менеджмента на основе комплексного исследования управленческих проблем внесли труды родоначальника школы человеческих отношений американского ученого Мэри Паркер Фоллетт (1868-1933). Комплексный подход предусматривал интеграцию гуманистических и меха- нистических, психологических и социальных аспектов управления за счет применения методов естественных и гуманитарных наук: «Надо помнить: нам никогда не удастся полностью разделить гуманистический и механистический аспекты. Исследование человеческих взаимоотношений в бизнесе и изучение технологии бизнеса взаимосвязаны» [8]. Фоллет подчеркивала определяющее влияние группы и общественных взаимодействий на формирование личности. «Истинное Я человека - это его Я в группе», поэтому «у человека не может быть прав отдельно от общества, независимо от общества или против общества» [16]. М. Фоллет является одной из первых ученых среди представителей западной управленческой мысли, которая указала на необходимость изучения процессов в динамике, отмечая, что ситуация всегда меняется во времени, что требует непрерывной координации социальных взаимодействий, мониторинга текущих процессов и контроля за выполнением решений.

Особое место в развитии школы человеческих отношений занимают идеи таких ученых - представителей биохевиризма, как А. Маслоу, Ф. Херцберг и др., которые рассматривали различные модели поведения людей в зависимости от изменений в мотивациях и потребностях.

Самой популярной классификацией потребностей человека, нашедшей широкое междисциплинарное применение в таких сферах знания, как биология, социология, психология, экономика, управление и др., выступает теория мотивации А. Маслоу («Теория человеческой мотивации», 1943). Несмотря на различия в мотивационной сфере различных людей, определяющих их социально-психологические особенности поведения, предлагаемая Маслоу иерархия потребностей позволяет обобщить необъятный перечень физиологических, социальных, экономических, духовных и иных потребностей человека в единую систему и структурировать их по принципу восхождения от простого к сложному. Действительно, совокупность мотивов, побуждающих к экономической деятельности, в целом динамична и составляет мотивационную сферу личности. Главные отношения, характеризующие мотивационную сферу личности - отношения иерархии мотивов, распределяемых во времени. Предлагаемое А. Маслоу распределение потребностей по ступеням представляет ди- 
намический процесс. Этим он подчеркивал, что речь здесь идет о времени, в большей или меньшей степени затрачиваемом на удовлетворение той или иной потребности [6].

Следует также упомянуть про один популярный способ оценки эффективности использования ресурсов - Правило Парето. Оно гласит, что восемьдесят процентов результата обеспечивается двадцатью процентами затрат. Закон был выведен экономистом Вильфредо Парето в XIX веке. При своих исследованиях он обратил внимание на то, что большая часть средств сосредоточена в руках меньшей части населения. Основываясь на этом, он вывел эту пропорцию, которую можно применить не только к ресурсам, но также и к другим объектам, процессам и явлениям. Если применить это правило к рабочему времени, то получается, что только $20 \%$ времени обеспечивает максимальный эффект, а дальнейшие усилия и потраченная энергия на получения полезности не равны затратам времени. Однако сам учёный не смог обосновать действие данного принципа. Позднее Иосиф Юран в ходе своих исследований подтвердил закон 80/20 и написал книгу, в которой он настаивал на внедрении данного принципа на производстве в целях повышения качества изготовляемой продукции и снижения доли брака.

Одной из первых работ по тайм-менеджменту, изданной в России, является «Ваше время в ваших руках» под авторством Лотара Зайверта [7]. В книге автор разделяет процесс управления на несколько этапов: постановка целей, планирование, принятие решений, реализация и организация, контроль, информация и коммуникация, претворение в практику. Каждый этап предполагает осуществление действий, которые необходимо предпринять или устранить. Например, планирование включает расстановку приоритетов, фиксацию результатов, соблюдение принципов тайм-менеджмента, принципа Альпа и др.

Среди отечественных ученых-исследователей в области тайм-менеджмента особого внимания заслуживают работы Г.А. Архангельского, посвященные проблемам организации и распределения времени. Наиболее известным его трудом является книга «Тайм-драйв. Как успевать жить и работать» [2]. Описанная автором методика мотивации, целеполагания, планирования и определения приоритетов, напоминает труд Дэвида Аллена. Но Глеб Архангельский при- водит примеры применения основ тайм-менеджмента и делится собственным опытом с учетом особенностей экономических и управленческих процессов в странах бывшего СССР.

Современный тайм-менеджмент рассматривает организацию времени в зависимости от жизненной позиции личности как инструмент для максимальной реализации человеческого потенциала в соответствии с его жизненными ценностями и целеполаганием. Особо значимым является не линейное распределение дел во времени по срочности, а расстановка приоритетов дел по важности. Речь идет о качестве использования времени, которое служит основным мотиватором в саморазвитии личности.

Ярким примером учета эффективности использования времени жизни выступает система А.А. Любищева, который на протяжении 56 лет фиксировал затраты времени на различные виды деятельности, определяя, таким образом, коэффициент полезного действия собственного времени. Благодаря данной системе он мог точно планировать свою научноисследовательскую деятельность на год и более. Благодаря сэкономленному времени он также изучал другие науки: математику, физику, философию. Согласно А.А. Любищеву: «Время помогает понять человеку смысл его деятельности. Время - это народное богатство, такое же как недра, лес, озера... С детства надо воспитывать любовь к природе и любовь ко времени. И учить, как беречь время, как его находить, как его добывать» $[4$, с. 149]. Наш взгляд, главное в системе Любищева то, что она заставляет задуматься над смыслом проведенного времени жизни, благодаря чему человек мотивирован на постановку целей и следованию им.

Таким образом, на основе проведенного анализа трудов, посвященных организации времени, можно сделать вывод о том, что современный тайм-менеджмент нацелен на умение человека управлять собой, эмоциями, мыслями, то есть действовать во времени осознанно. Так или иначе, основная цель тайм-менеджмента повышение результативности деятельности за счет эффективной организации времени, остается неизменной.

Однако традиционные подходы в тайм-менеджменте не учитывают, что современное общество нелинейно - оно множественно, вариативно. Важным принципом мягкого, нелинейного управления временем является сво- 
евременность управленческого воздействия, определяемого чувством нужного момента. Управляющий должен не только интуитивно чувствовать, но и уметь анализировать состояние социального субъекта, прогнозировать в его развитии кризисы и подъемы. Жесткое управление временем подчиняет его поведение ритму и временным границам, запланированным управляющим субъектом [1].

Природа времени и субъективна на основе интуитивного восприятия его течения, и объек- тивна, позволяющая рассматривать и выделять свойства времени как физического процесса. В связи с этим, современная концепция тайм-менеджмента, на наш взгляд, должна учитывать все многообразие и многогранность человеческой жизни и деятельности, выражаясь словами Даниила Гранина при описании Системы жизни А.А. Любищева, быть подобной «эйнштейновской теории относительности - новые свойства времени, его возможности, его неоднородность, его новые «системы отсчета» $[4$, с. 20].

\section{Библиографический список}

1. Амбарова П.А. Управление временем: смена управленческой парадигмы // Известия УрФУ. Сер. 1. Проблемы образования, науки и культуры. 2015. № 1. С. 132-144.

2. Архангельский Г. А. Тайм-драйв. Как успевать жить и работать // Манн, Иванов и Фербер - 2019. - 256 с.

3. Балацкий Е.В. Свободное время как фактор экономического равновесия / Е.В. Балацкий // Вестник РАН.1999. - № 11. - С. 1018-1028.

4. Гранин Д. Эта странная жизнь / Д. Гранин.- СПбГУП. -1998.

5. Демина В.В. Теоретико-методологические аспекты формирования спроса и предложения на рабочее время / В.В. Демина // Вестник МГОУ. Серия: Экономика. - 2011.- № 2.

6. Желаева С.Э. Методология исследования времени в процессе самоорганизации экономики / С.Э. Желаева.Улан-Удэ.-Издательство ВСГУТУ.-2017.-243 с.

7. Зайверт Л. Ваше время - в Ваших руках: (Советы руководителям, как эффективно использовать рабочее время): Пер. с нем./Авт. предисл. В.М. Шепель.-М.: Экономика, 1990.- 232 с. - ISBN5-282-00625-1.

8. Крейнер С. Библиотека избранных трудов о бизнесе. Книги, сотворившие менеджмент / пер. с англ. А. Трактинский. Москва: Олимп-Бизнес, 2005. С. 113. М.П.

9. Крючков В.Н. Нелинейность времени в менеджменте/ В.Н. Крючков.-Омск.-Издательство ОМгУ.-2009.93 с.

10. Леванов А.Д. Время в экономическом измерении / А.Д. Леванов. М.: Социум, 1994.

11. Маевский В.И. Воспроизводство основного капитала и экономическая теория / В.И. Маевский // Вопросы экономики. - 2010.- № 3.

12. Маевский В.И. Новый взгляд на теорию воспроизводства: монография / В.И. Маевский, С.Ю. Малков.- М.: ИНФРА-М, 2014. - 238 с.

13. Маркс К., Энгельс Ф. Сочинения / К. Маркс, Ф. Энгельс. 2-е изд. Т. 46, ч. І. М.: Политиздат, 1968.- Институт марксизма-ленинизма при ЦК КПСС.

14. Толокина Е.Л. Свободное время как категория теоретической экономики / Е.Л. Толокина // Теоретическая экономика. - 2012. - № 5 .

15. Чемыхин В.А. Время и экономика: Очерки политической экономии времени в концепции К. Маркса: монография / В.А. Чемыхин; Курск гос. техн. ун-т.- Курск, 2008. - 224 с.

16. Follett M.P. The New State-Group Organization: The Solution for Popular Government. London: Longmans, Green, 1918. Р. 7; Шелдрейк Дж. Теория менеджмента: от тейлоризма до японизации / пер с англ. под ред. В.А. Спивака. Санкт-Петербург: Питер, 2001. С. 131-132. 